\title{
Bone morphogenetic protein signalling in heritable versus idiopathic pulmonary hypertension
}

\author{
L. Dewachter*, S. Adnot*, C. Guignabert*, L. Tu*, E. Marcos*, E. Fadel ${ }^{\#}$, \\ M. Humbert ${ }^{\ddagger}$, P. Dartevelle ${ }^{\#}$, G. Simonneau ${ }^{\dagger}$, R. Naeije ${ }^{+}$and S. Eddahibi*
}

ABSTRACT: Mutations in the gene encoding bone morphogenetic protein (BMP) receptor type 2 (BMPR-2) have been reported in pulmonary arterial hypertension (PAH), but their functional relevance remains incompletely understood.

BMP receptor expression was evaluated in human lungs and in cultured pulmonary artery smooth muscle cells (PASMCs) isolated from 19 idiopathic PAH patients and nine heritable PAH patients with demonstrated BMPR-2 mutations. BMP4-treated PASMCs were assessed for Smad and p38 mitogen-activated protein kinase (MAPK) signalling associated with mitosis and apoptosis.

Lung tissue and PASMCs from heritable PAH patients presented with decreased BMPR-2 expression and variable increases in BMPR-1A and BMPR-1B expression, while a less important decreased BMPR-2 expression was observed in PASMCs from idiopathic PAH patients. Heritable PAH PASMCs showed no increased phosphorylation of Smad1/5/8 in the presence of BMP4, which actually activated the p38MAPK pathway. Individual responses varied from one mutation to another. PASMCs from PAH patients presented with an in vitro proliferative pattern, which could be inhibited by BMP4 in idiopathic PAH but not in heritable PAH. PASMCs from idiopathic PAH and more so from heritable PAH presented an inhibition of BMP4-induced apoptosis.

Most heterogeneous BMPR-2 mutations are associated with defective Smad signalling compensated for by an activation of p38MAPK signalling, accounting for PASMC proliferation and deficient apoptosis.

KEYWORDS: Bone morphogenetic protein receptor type 2, intracellular signal transduction, mutation, pulmonary hypertension, smooth muscle cells, vascular remodelling

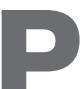

ulmonary arterial hypertension $(\mathrm{PAH})$ is an uncommon disease with a poor prognosis and mysterious pathobiology, characterised by a progressive increase in pulmonary vascular resistance and eventual right ventricular failure [1]. Mutations of bone morphogenetic protein (BMP) receptor type 2 (BMPR-2), a member of the transforming growth factor (TGF)- $\beta$ receptor family, have been reported in a high proportion of patients with the heritable form of the disease, and in $10-30 \%$ of patients with sporadic idiopathic PAH [2]. To date, more than 200 distinct BMPR-2 mutations have been described, widely dispersed across the gene, with the majority predicting premature truncation of the transcript [3]. BMPR signalling involves heterodimerisation of two transmembrane serine/threonine-kinase receptor chains, the constitutively active BMPR-2 and the corresponding type 1 receptor BMPR-1A/ALK3 or
BMPR-1B/ALK6 $[4,5]$. With interaction of a ligand, for example BMP4, the activated kinase domain of BMPR-2 phosphorylates the corresponding BMPR-1, which in turn initiates intracellular signalling through the phosphorylation of a set of BMP-restricted Smad proteins (Smad1/5/8). Subsequently, these phosphorylated Smads associate with Smad4, translocate to the nucleus and then modulate the transcription of target genes. Alternative Smad-independent signalling pathways involving mitogen-activated protein kinase (MAPK), including extracellular signal-regulated kinase (ERK)1/2, Jun N-terminal kinase (JNK) and p38MAPK, have been reported to be activated by BMP ligands [6]. The resulting imbalance is believed to be the cause of a proliferation of pulmonary artery smooth muscle cells (PASMCs), a major component of pulmonary arteriolar remodelling in PAH [1].

\section{AFFILIATIONS}

*INSERM U955, Institut Mondor de recherche biomédicale, Créteil, \#UPRES EA2705, Laboratoire de

Chirurgie Expérimentale, Centre Chirurgical Marie Lannelongue, Université Paris-Sud 11, Le Plessis Robinson,

"INSERM U764, UPRES EA2705,

Service de Pneumologie, Centre

National de Référence de

l'Hypertension Artérielle Pulmonaire, Hôpital Antoine-Béclère, AssistancePublique Hôpitaux de Paris,

Université Paris-Sud 11, Clamart,

France, and

+Laboratory of Physiology, Faculty of Medicine, Free University of

Brussels, Brussels, Belgium.

\section{CORRESPONDENCE}

L. Dewachter

Dept of Physiology, Faculty of Medicine

Free University of Brussels

808 Lennik Road

1070 Brussels

Belgium

E-mail: Idewacht@ulb.ac.be

Received:

Dec 022008

Accepted after revision:

March 122009

First published online:

March 262009 
It is of interest that the histopathology and clinical picture of PAH with or without BMPR-2 mutations appear similar, except for an earlier age of onset, more severe haemodynamic compromise at diagnosis and less common reversibility at vasodilator testing $[7,8]$. Therefore, the functional consequences of $B M P R-2$ mutations remain incompletely understood, but it may be hypothesised that their phenotypic impact may vary with type of mutation or interaction with alternative signalling pathways.

It has previously been reported that PASMCs from idiopathic $\mathrm{PAH}$ patients present with an in vitro proliferative phenotype $[9,10]$. In the present study, we investigated the effects of BMP4 on Smad and p38MAPK signalling associated with mitosis and apoptosis in cultured PASMCs isolated from idiopathic PAH patients without detected mutations and from heritable PAH patients with mutations. The results are in keeping with the notion of a crucial role for $\mathrm{BMP} / \mathrm{Smad}$ signalling in the prevention of abnormal growth and apoptosis of PASMCs that is lost in most but not all types of mutations.

\section{METHODS}

\section{Tissue samples}

Lung tissue and pulmonary arteries were sampled at lung transplantation and sequenced to screen for BMPR-2 mutations. After confirmatory cross-check with medical records, patients with PAH were segregated into two groups, according to the presence or absence of mutations. These two groups were respectively called heritable $\mathrm{PAH}(\mathrm{n}=9)$ and idiopathic PAH $(\mathrm{n}=19)$ patients. Pulmonary specimens were also sampled in control subjects $(n=10)$ at lobectomy or pneumonectomy for a suspected localised lung tumour. These control subjects did not bear any BMPR-2 mutations or polymorphisms.

All PAH patients were in New York Heart Association functional class III or IV and were treated with i.v. epoprostenol. In the control subjects, transthoracic echocardiography was performed pre-operatively to rule out pulmonary hypertension, and pulmonary arteries were sampled at a distance from tumour areas. The study was approved by the local Institutional Review Board (Ethics Committee, CPP Ile-deFrance VII, Le Kremlin-Bicêtre, France), and patients provided informed consent prior to their contribution to the study.

\section{Screening for mutations in the gene encoding the BMPR-2 receptor}

Mutations in the BMPR-2 gene in lung specimens from patients with PAH $(n=28)$ were screened as previously described [11, $12]$. Briefly, the entire protein-coding region (sequence corresponding to exons $1-13$ of the BMPR-2 gene) was amplified from genomic DNA samples by PCR with specific primers. PCR products were then separated by electrophoresis in a $1 \%$ agarose gel and purified using the QIAquick PCR purification kit (QIAGEN, Courtaboeuf, France). Amplified and purified fragments were sequenced wih a dye-terminator cycle-sequencing system (ABI PRISM 377, Perkin-Elmer Applied Biosystems, Courtaboeuf).

\section{Culture of human PASMCs and pulmonary microvascular endothelial cells}

Human PASMCs were cultured from explants of pulmonary arteries (1.5-10 $\mathrm{mm}$ in diameter) derived from previously described patient groups transplanted for heritable and idiopathic $\mathrm{PAH}$, and also from controls. PASMCs were cultured in 10\% fetal calf serum (FCS) in Dulbecco's modified Eagle medium (DMEM) and used between passages three and six, as previously described [13]. The phenotype of cultured PASMCs was assessed for expression of muscle-specific contractile and cytoskeletal proteins, including smooth muscle $\alpha$-actin ( $\alpha$-SMA), desmin and vinculin [13].

Human pulmonary microvascular endothelial cells (PECs) were obtained by dispase I (Roche Diagnostics, Penzbeg, Germany) digestion followed by immunomagnetic purification with anti-platelet endothelial cell adhesion molecule-1 (CD31) monoclonal antibody-labelled Dynabeads (Dynal Biotech, Compiegne, France) of a fragment of lung tissue isolated from heritable and idiopathic PAH patients and controls, as previously described $[9,14]$. To characterise the endothelial phenotype, PECs were labelled with acetylated low-density lipoprotein coupled to a fluorescent carbocyanine dye $\left(1,1^{\prime}\right.$ dioctadecyl-3,3,3', 3' -tetramethylindocarbocyanine perchlorate (Dil-Ac-LDL); Tebu, Le Perray en Yvelines, France) and stained with antibodies against the endothelial cell-specific lectin Ulex europaeus agglutinin-1 (UEA-1; Sigma-Aldrich, Irvine, UK) [15]. Experiments were also performed with monoclonal antibodies against desmin and vimentin (Dako, Glostrup, Denmark). Cells with positive staining for Dil-Ac-LDL and UEA-1 and negative staining for desmin and vimentin were taken as endothelial cells and constituted $>95 \%$ of our PEC cultures. PECs were used between passages three and six $[9,14]$.

\section{RNA extraction and cDNA preparation}

Total RNA was prepared from snap-frozen human lung tissue samples (weight $100 \mathrm{mg}$ ) by homogenisation according to the method of CHOMCZYNSKI and SACCHI [16], using TRIzol reagent (Invitrogen, Cergy-Pontoise, France). Total RNA was extracted from growth-arrested primary cultures of human PASMCs and PECs using Qiagen RNeasy Mini kit (QIAGEN), according to the manufacturer's instructions. RNA concentration was determined by standard spectrophotometric techniques and the RNA integrity was assessed by visual inspection of ethidium bromide-stained denaturing agarose gels. Firststrand cDNA synthesis was carried out using SuperScript II Reverse Transcriptase System (Life Technologies, Inc., Carlsbad, CA, USA), as previously described [9, 14].

\section{Real-time quantitative PCR}

Real-time quantitative (RTQ)-PCR primers were designed using the computer program Primer3 (Primer Express Software, Applied Biosystems) for human BMPR-1A, BMPR1B, BMPR-2, Bax and Bcl2 mRNA, and for 18s ribosomal RNA as a housekeeping gene. To avoid inappropriate amplification of residual genomic DNA, intron-spanning primers were selected. RTQ-PCR was performed in triplicate on an ABI PRISM 7000 (Applied Biosystems, Foster City, CA, USA), in mixtures of $12.5 \mu \mathrm{L}$ Sybr Green PCR Master Mix (Applied Biosystems, Warrington, UK), $300 \mathrm{nM}$ (each) primer and $5 \mu \mathrm{L}$ of diluted template DNA in a total volume of $25 \mu \mathrm{L}$. Signal detection and analysis of results were performed with ABI PRISM 7000 sequence detection software (Applied Biosystems). Relative quantification was achieved with the comparative $2^{-\Delta \Delta \mathrm{Ct}}$ method by normalisation with $18 \mathrm{~s}$ ribosomal RNA. For 
assays of Bax and Bcl2 mRNAs, PASMCs were seeded and synchronised. The cells were then exposed to BMP4 $\left(100 \mathrm{ng} \cdot \mathrm{mL}^{-1}\right)$ for $4 \mathrm{~h}$ and then used for mRNA extraction and RTQ-PCR.

\section{Protein extraction and BMPR-1A, BMPR-1B and BMPR-2 western blotting}

Proteins were extracted from snap-frozen tissue samples (weight $100 \mathrm{mg}$ ) by homogenisation in an appropriate amount of homogenising buffer (Complete Mini Protease Inhibitor Cocktail (Roche Diagnostics, Mannheim, Germany) in PBS and $0.1 \%$ Triton X-100). The homogenates were centrifuged at $4{ }^{\circ} \mathrm{C}$ and the supernatants were collected. After determination of the protein concentration using the method of BRADFORD [17], $40 \mu \mathrm{g}$ of protein from each lung sample were resuspended in $3 \times$ Laemmli buffer, boiled for $5 \mathrm{~min}$, and separated on $10 \%$ acrylamide gel by electrophoresis. Proteins were electrophoretically transferred to a nitrocellulose membrane (SigmaAldrich, Irvine, UK) for $1 \mathrm{~h}$ at room temperature. After blocking with $5 \%$ bovine serum albumin (BSA) in $1 \times$ Tween (T)-TBS (10 mM Tris- $\mathrm{HCl} \mathrm{pH} 8.0,150 \mathrm{mM} \mathrm{NaCl}$ and $0.1 \%$ Tween 20) for $2 \mathrm{~h}$ at room temperature, the membrane was washed three times with T-TBS at room temperature for $5 \mathrm{~min}$. The membrane was incubated with goat anti-human BMPR1A, BMPR-1B or BMPR-2 antibody (1:500; R\&D systems, Minneapolis, MN, USA) at $4{ }^{\circ} \mathrm{C}$ overnight with rocking. Then the membrane was washed three times for $5 \mathrm{~min}$ and incubated with the secondary antibody (rabbit anti-goat immunoglobulin (Ig)G conjugated with horseradish peroxidase; Dako, Glostrup, Denmark; 1:2,000) for $1 \mathrm{~h}$ at room temperature. Immunoreactive bands were detected using the enhanced chemiluminescence western blotting analysis system (Amersham Pharmacia Biosciences, Little Chalfont, UK) and quantified by laser densitometry. Relative quantification was performed by normalisation with $\beta$-actin (Sigma-Aldrich, St Louis, MO, USA).

\section{Immunoblotting for BMP signalling pathways}

PASMCs were plated in fresh 10\% FCS/DMEM medium for $24 \mathrm{~h}$ and then quiesced for $48 \mathrm{~h}$ in serum-free medium. BMP4 $\left(100 \mathrm{ng} \cdot \mathrm{mL}^{-1}\right)$ or vehicle was then added to the cells for $20 \mathrm{~min}$. Protein was harvested by washing cells in cold PBS and by scraping in $300 \mu \mathrm{L}$ of $1 \times$ sample loading buffer (Tris- $\mathrm{HCl} \mathrm{pH} \mathrm{7.4,}$ $\mathrm{NaCl}, \mathrm{NaF}$, sodium pyrophosphate (all at $25 \mathrm{mM}$ ), sodium vanadate $(1 \mathrm{mM})$, EDTA, EGTA (both at $2.5 \mathrm{mM})$, phenylmethylsulfonyl fluoride $(1 \mathrm{mM})$, aprotinine, leupeptine (both at $5 \mu \mathrm{g} \cdot \mathrm{mL}^{-1}$ ), SDS, deoxycholate and NP-40 (all at $0.50 \%$ )) on ice. The samples were then stored at $-20^{\circ} \mathrm{C}$. After determination of the protein concentration, using the method of BRADFORD [17], samples $(20 \mu \mathrm{g})$ were resuspended in $3 \times$ Laemmli buffer, boiled at $95^{\circ} \mathrm{C}$ for $5 \mathrm{~min}$ and electrophoresed on acrylamide gels $(10 \%)$. Immunoblotting assays were performed as described above with monoclonal mouse anti-human phospho-p38 ${ }^{\mathrm{MAPK}(\mathrm{Thr} 180 / \mathrm{Tyr} 182)}$ (1:1000; Cell Signaling Technology Inc., Danvers, MA, USA), polyclonal rabbit anti-human phospho-Smad1 $1^{\text {(Ser463/465) }}$ / Smad5 ${ }^{(\text {Ser463/465) }} /$ Smad $^{(\text {Ser426/428) }} \quad$ (1:1000; Cell Signaling Technology Inc.) and polyclonal goat anti-human total Smad 1/ 5/8 (1:1000; Santa-Cruz Biotechnology, Santa Cruz, CA, USA). Relative quantification was performed by normalisation with total Smad1/5/8 for phospho-Smad1/5/8 and $\beta$-actin (SigmaAldrich, Lyon, France) for p38MAPK. Treatment with
$100 \mathrm{ng} \cdot \mathrm{mL}^{-1}$ for $20 \mathrm{~min}$ was chosen based on preliminary studies of BMP4 concentrations in relation to the capacity to activate downstream signalling pathways and to inhibit growth-promoting activity of mitogenic agents on PASMCs [18, 19].

\section{PASMC proliferation assays}

The growth of human cultured PASMCs was determined by $\left[{ }^{3} \mathrm{H}\right]$-thymidine incorporation, representing DNA synthesis. Briefly, PASMCs were seeded in 24-well plates in 10\% FCS/ DMEM at a density of $5 \times 10^{4}$ cells $^{\prime}$ well ${ }^{-1}$ and allowed to adhere for $24 \mathrm{~h}$. The medium was then removed and the cells subjected to growth arrest by incubation with serum-free DMEM. After $48 \mathrm{~h}$, the medium was replaced with fresh DMEM containing $10 \%$ FCS or $10 \mathrm{ng} \cdot \mathrm{mL}^{-1}$ platelet-derived growth factor (PDGF) in the presence or absence of $100 \mathrm{ng} \cdot \mathrm{mL}^{-1} \mathrm{BMP} 4$. PASMC proliferation was also assessed in response to $10 \%$ FCS and $10 \mathrm{ng} \cdot \mathrm{mL}^{-1}$ PDGF alone. For each condition, $\left[{ }^{3} \mathrm{H}\right]$-thymidine $\left(0.6 \mu \mathrm{Ci} \cdot \mathrm{mL}^{-1}\right)$ was added to each well. After incubation for $24 \mathrm{~h}$, the cells were washed twice with PBS, treated with icecold $10 \%$ trichloroacetic acid and neutralised with $0.1 \mathrm{~N} \mathrm{NaOH}$ $\left(0.5 \mathrm{~mL} \cdot\right.$ well $\left.^{-1}\right)$. $\left[{ }^{3} \mathrm{H}\right]$-thymidine incorporation into DNA was counted and reported as counts per minute per well.

\section{Apoptosis assays}

Apoptosis evaluation was performed by flow cytometry analysis of the DNA content by propidium iodide incorporation and RTQ-PCR analysis of the $\mathrm{Bax} / \mathrm{Bcl} 2$ ratio. For flow cytometry analysis of DNA content, PASMCs were seeded and treated for $24 \mathrm{~h}$ with fresh serum-free DMEM in the presence or absence of BMP4 $\left(100 \mathrm{ng} \cdot \mathrm{mL}^{-1}\right)$. Culture medium was removed and saved. Cells were trypsinised and returned to the medium they had grown in and then centrifuged. Cells were then washed twice in ice-cold PBS and stored at $4{ }^{\circ} \mathrm{C}$ in $75 \%$ ethanol. Fixed cells were centrifuged, washed with PBS and incubated with $200 \mu \mathrm{L}$ Rnase I $\left(1 \mathrm{mg} \cdot \mathrm{mL}^{-1}\right.$; Invitrogen $)$ and $200 \mu \mathrm{L}$ of propidium iodide $\left(1 \mathrm{mg} \cdot \mathrm{mL}^{-1}\right.$; Sigma-Aldrich, Lyon, France). Cells were incubated at room temperature for $1 \mathrm{~h}$ in the dark. Samples were analysed by flow cytometry. The red fluorescence of single events was recorded using a laser beam at $488 \mathrm{~nm}$ excitation wavelength with $610 \mathrm{~nm}$ as emission wavelength, to measure the DNA index. For Bax/Bcl2 ratio determination, PASMCs were seeded, synchronised and treated for $4 \mathrm{~h}$ as described above. mRNA extraction, cDNA synthesis and RTQ-PCR were performed to determinate the expression of pro-apopototic Bax and anti-apoptotic $\mathrm{Bcl} 2$ genes compared with $18 \mathrm{~s}$ as a housekeeping gene, as described above.

\section{Statistical analyses}

All data are reported as mean \pm SEM. Effects of BMPR-2 mutations and BMP4 treatment were analysed by repeatedmeasures ANOVA. When the F-ratio of the ANOVA reached a critical value of $\mathrm{p}<0.05$, nonparametric Mann-Whitney tests were used to compare specific situations [20]. A linear squared regression analysis was used to calculate correlations between pulmonary vascular resistance and content (mRNA and protein) of the investigated BMP signalling molecules [20].

\section{RESULTS}

Clinical and haemodynamic characteristics of $P A H$ patients There were no differences between $\mathrm{PAH}$ patients with and without BMPR-2 mutations in terms of age $(41 \pm 2$ versus 
$39 \pm 3$ yrs), female to male sex ratio $(10 / 9$ versus $5 / 4)$, mean pulmonary artery pressure (62 \pm 2 versus $63 \pm 3 \mathrm{mmHg})$, pulmonary vascular resistance $\left(20 \pm 1\right.$ versus $\left.20 \pm 2 \mathrm{U} \cdot \mathrm{m}^{-2}\right)$ and cardiac index $\left(2.19 \pm 0.09\right.$ versus $\left.2.41 \pm 0.25 \mathrm{~L} \cdot \mathrm{min}^{-1} \cdot \mathrm{m}^{-2}\right)$. None of the patients presented with reversibility at vasodilator testing.

\section{Identification and description of BMPR-2 mutations}

Germline mutations in the 13 exons encoding BMPR-2 were identified in the nine heritable $\mathrm{PAH}$ patients (fig. 1). Three heterozygous nonsense mutations were identified in exons 1 (W16X), 2 (W70X) and 3 (S107X), which encode part of the extracellular domain of BMPR-2. One mutation consisted of total deletion of exon 1 ( $\Delta$ exon 1$)$. Two mutations were found in exon 5, which encodes the transmembrane domain of BMPR-2: one heterozygous nonsense mutation (E195X) and one causing loss of $22 \mathrm{bp}$ ( $22 \mathrm{bp}$ del). Two heterozygous missense mutations and one nonsense mutation were identified respectively in exons 7 (S301P) and 11 (R491W and Q495X), which encode parts of the kinase domain of BMPR-2. No ALK-1 mutation was found in the PAH patients with and without mutations.

\section{Pulmonary and cellular expression of BMPRs}

The expression of BMPR-1A mRNA and protein was increased in lung tissue from both heritable and idiopathic patients (figs 2a and 3a), but mRNA expression was only increased in PASMCs from idiopathic PAH patients (fig. $2 b$ ), and was not different from controls in PECs from heritable and idiopathic PAH patients (fig. 2c). The expression of BMPR-1B mRNA was increased in PASMCs from heritable $\mathrm{PAH}$ patients only (fig. 2e). The expression of BMPR-2 mRNA and protein was decreased in lung tissue from heritable PAH only (figs $2 \mathrm{~g}$ and $3 \mathrm{c})$, and the mRNA expression was decreased in PASMCs from both heritable and idiopathic PAH (fig. 2h), and was not different from controls in PECs (fig. 2i). However, as indicated by relatively large SEM values, the increased expression of BMPR-1A and BMPR-1B and decreased expression of BMPR-2 in PASMCs varied greatly from one mutation to another, with no consistent pattern (fig. 4). No correlation was found between pulmonary vascular resistance and lung expression of BMPR-1A, BMPR-1B and BMPR-2 proteins.

\section{Differential effects of BMP4 on Smad and p38MAPK signalling}

BMP4 (100 $\mathrm{ng} \cdot \mathrm{mL}^{-1}$ for $20 \mathrm{~min}$ ) induced the activation (phosphorylation) of Smad1/5/8 in PASMCs isolated from idiopathic PAH patients and controls (fig. 5), indicating that the transmission of BMP signalling was intact in these cells. In contrast, no BMP4-induced phosphorylation of Smad1/5/8 was observed in PASMCs from heritable PAH, with the exception of the $22 \mathrm{bp}$ del mutation (fig. 5c). BMP4 activated p38MAPK signalling in PASMCs from heritable PAH patients (with the exception of the PASMCs with $22 \mathrm{bp}$ del mutation) but not from idiopathic PAH patients or controls (fig. 6).

\section{Effects of BMP4 on PASMC proliferation induced by serum and PDGF treatment}

PASMCs isolated from heritable and idiopathic PAH exhibited an increased proliferation, as assessed by $\left[{ }^{3} \mathrm{H}\right]$-thymidine incorporation, in the presence of $10 \%$ serum but not $10 \mathrm{ng} \cdot \mathrm{mL}^{-1}$ PDGF (fig. 7). The addition of BMP4 induced an inhibition of $\left[{ }^{3} \mathrm{H}\right]$-thymidine incorporation in both serum- and PDGF-treated PASMCs from idiopathic PAH and controls, but not in PASMCs from heritable PAH patients. The absence of BMP4-induced inhibition of proliferation was observed in PASMCs from all the heritable PAH patients, except in the patient with the $22 \mathrm{bp}$ del mutation.

\section{Effects of BMP4 on PASMC apoptosis}

Flow cytometry analysis showed that BMP4 (10 and $100 \mathrm{ng} \cdot \mathrm{mL}^{-1}$ for $24 \mathrm{~h}$ ) increased apoptotic rates in PASMCs from idiopathic PAH patients and controls but to a lesser extent in PASMCs from idiopathic PAH and not from heritable PAH patients (fig. 8a). The Bax/Bcl-2 pro-apoptotic ratio was increased by BMP4 at $100 \mathrm{ng} \cdot \mathrm{mL}^{-1}$ in PASMCs from controls and idiopathic $\mathrm{PAH}$, but not from heritable $\mathrm{PAH}$ patients (fig. 8b)

\section{DISCUSSION}

The present results show that 1) lung tissue and PASMCs, but not PECs, from heritable PAH patients present with decreased expression of BMPR-2 and variable increases in the expression of BMPR1-A and BMPR-1B, while only a (relatively less important) decreased expression of BMPR-2 is observed in

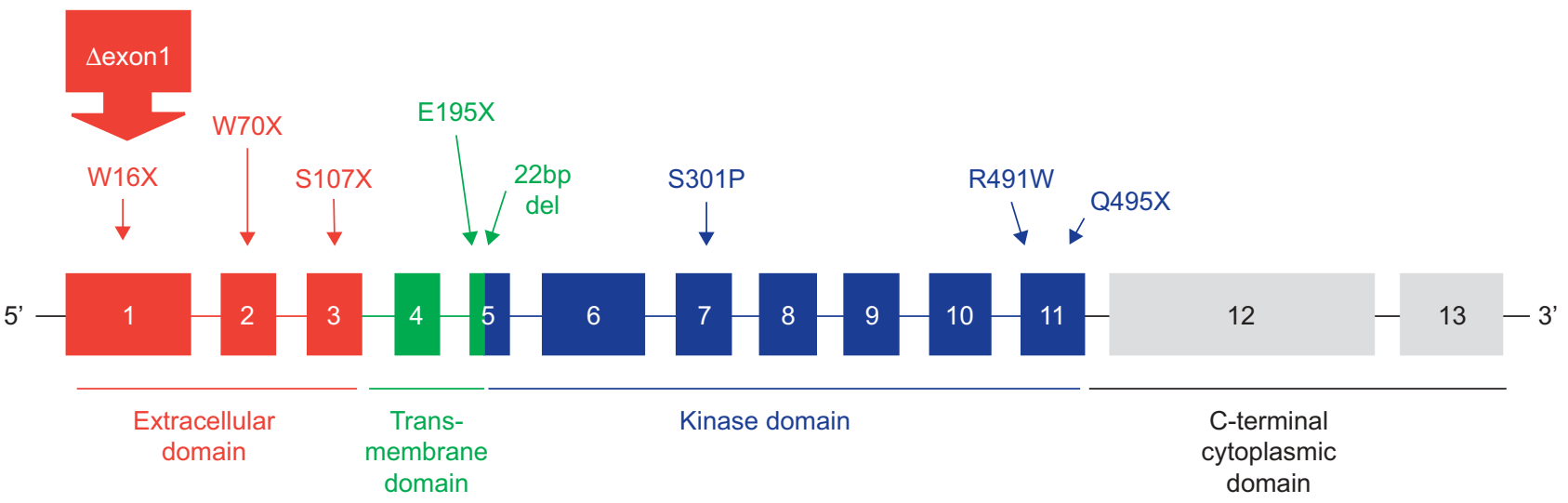

FIGURE 1. Genetic characteristics of patients. Schematic representation of bone morphogenetic protein receptor type 2 (BMPR-2) functional domains, demonstrating the range of BMPR-2 mutations studied in this study and indicating the nature of amino acid substitution or nonsense mutations $(X)$. 

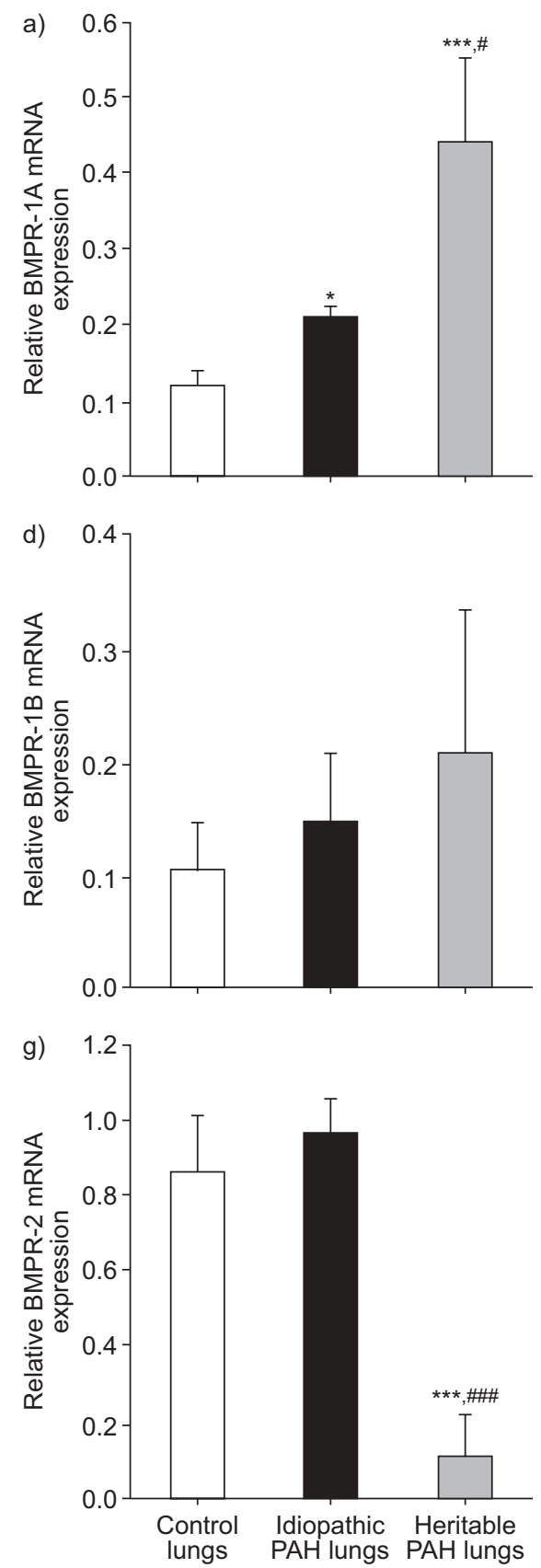

b)

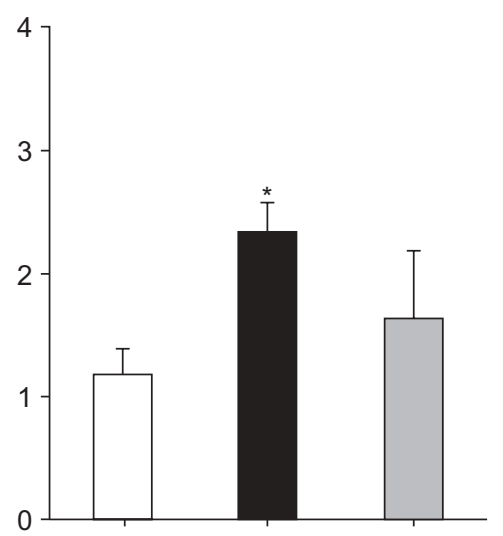

e)

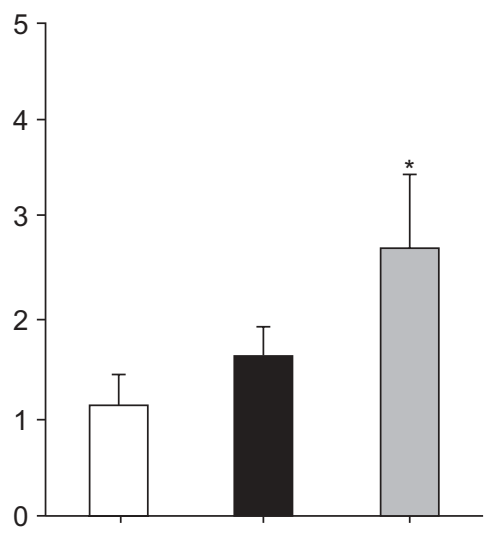

h)

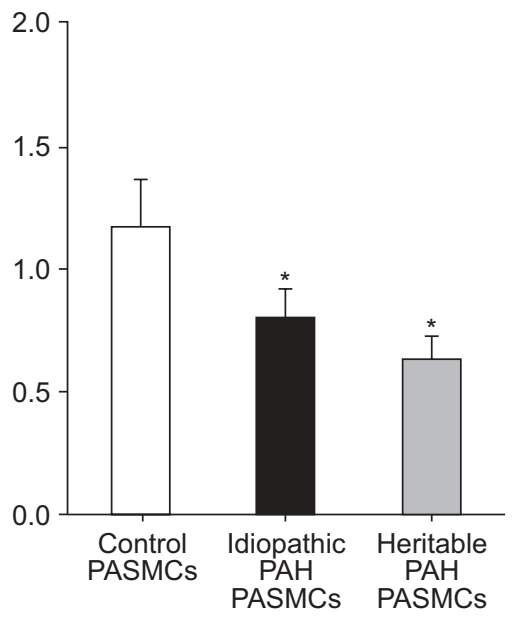

c)

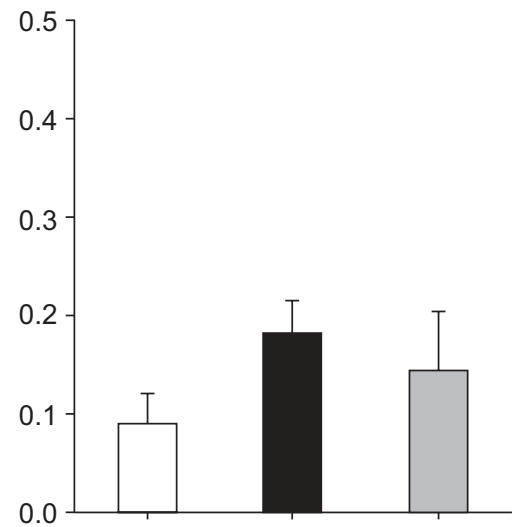

f)

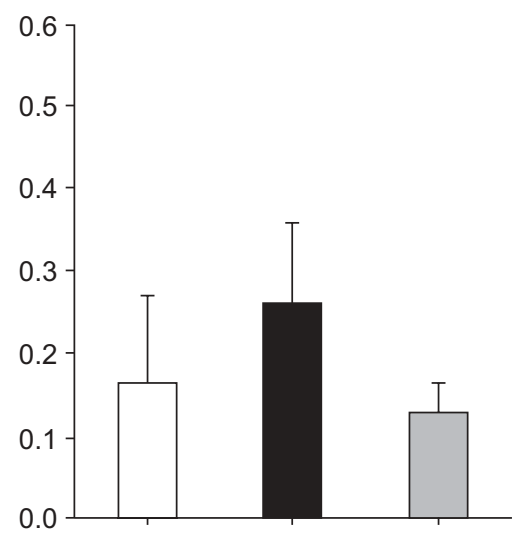

i)

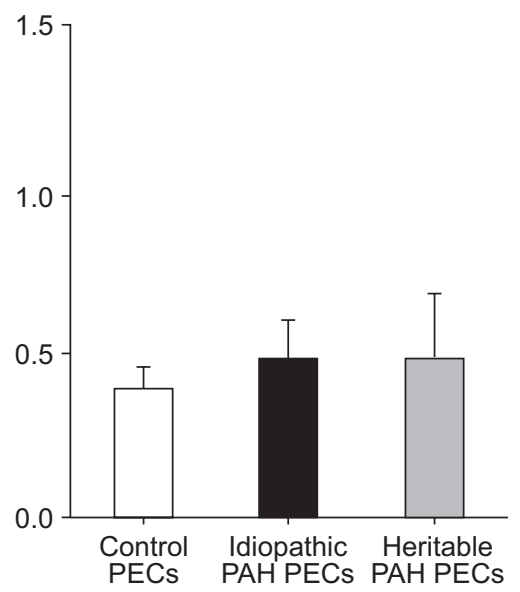

FIGURE 2. Relative a-c) bone morphogenetic protein receptor type 1 A (BMPR-1A), d-f) BMPR-1B and g-i) BMPR-2 mRNA expression. Whole lung tissue samples (a, $d$ and g), cultured pulmonary artery smooth muscle cells (PASMCs; b, e and h) and pulmonary microvascular endothelial cells (PECs; c, $f$ and i) from controls ( $\square$ ), pulmonary arterial hypertension (PAH) patients without ( $\mathbf{\square}$; idiopathic PAH) and with BMPR-2 mutations ( $\square$; heritable PAH) were assessed by real-time quantitative PCR. Results are expressed as mean \pm SEM. Statistical differences were assessed by the Mann-Whitney test. ${ }^{*}: p<0.05$ versus control conditions; ${ }^{* *}$ : $p<0.001$ versus control conditions; \#: $\mathrm{p}<0.05$ idiopathic PAH versus heritable PAH conditions; ${ }^{\# \#: ~} \mathrm{p}<0.001$ idiopathic PAH versus heritable PAH conditions.

PASMCs from idiopathic PAH patients; 2) PASMCs from heritable PAH patients show no BMP4-induced Smad 1/5/8 phosphorylation but do show BMP4-induced activation of the p38MAPK pathway; 3) PASMCs from PAH patients present with an in vitro proliferative and anti-apoptotic pattern, which can be inhibited by BMP4 in idiopathic PAH but not in heritable $\mathrm{PAH}$; and 4) individual responses vary from one mutation to another, with in particular PASMCs from $\mathrm{PAH}$ patients with the $22 \mathrm{bp}$ del mutation showing no difference compared with PASMCs from idiopathic PAH patients without identified mutations. The present work confirmed previous studies about BMPR-2 signalling in PAH and presented, for the first time, a large in vitro comparison of PASMCs with and without naturally occurring $B M P R-2$ mutations. 
a)
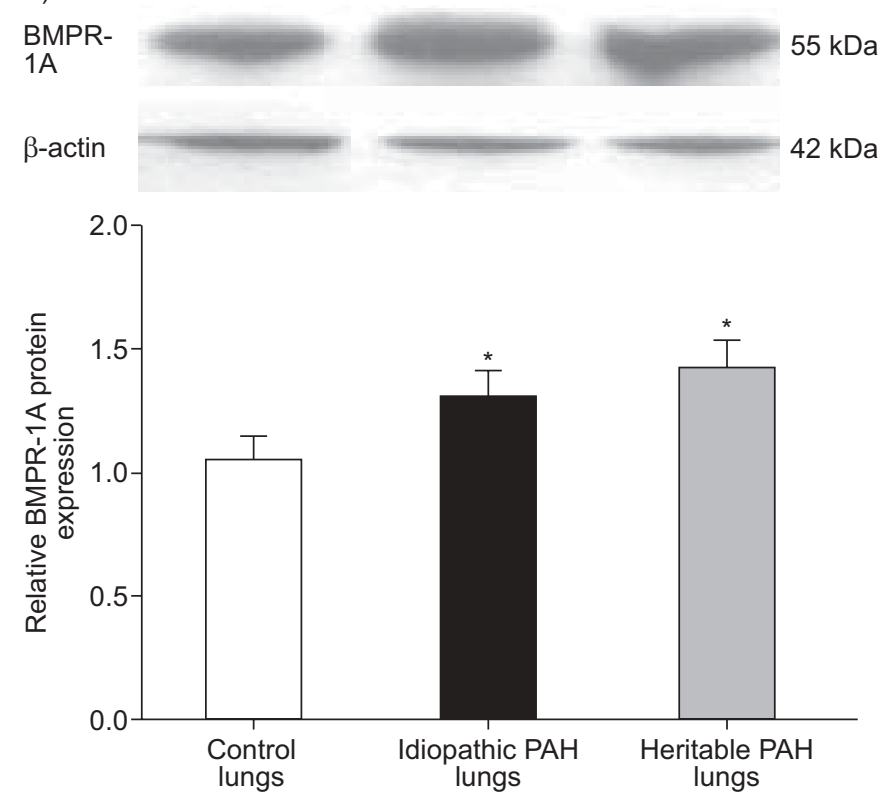

c)
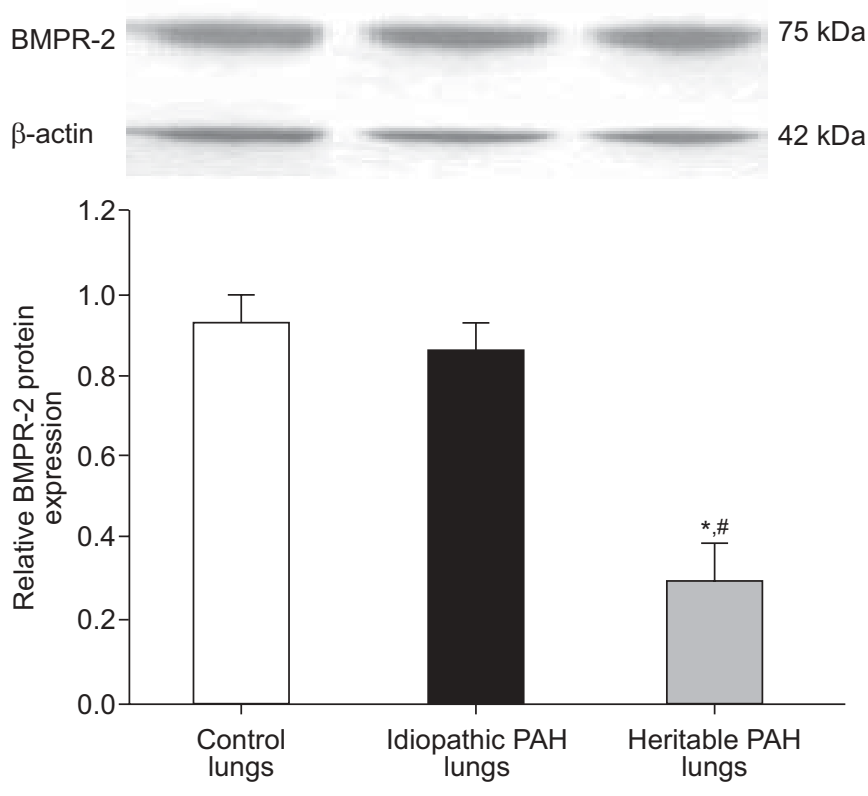

Although BMPR-2 mutations are identified in the majority of heritable $\mathrm{PAH}$ patients, and carry a significant risk of developing the disease in asymptomatic carriers, two large clinical studies have failed to disclose differences in clinical presentation, haemodynamics and histopathology between heritable and idiopathic PAH patients, except for an earlier onset of the disease, more compromised haemodynamics and maybe a less frequent reversibility at vasodilator testing in heritable PAH [7, 8]. These observations suggest heterogeneous functional consequences of the various $>200$ BMPR-2 mutations hitherto reported, and also interactions with coexisting signalling abnormalities. In the present study, there was no difference in clinical presentation of heritable and b)
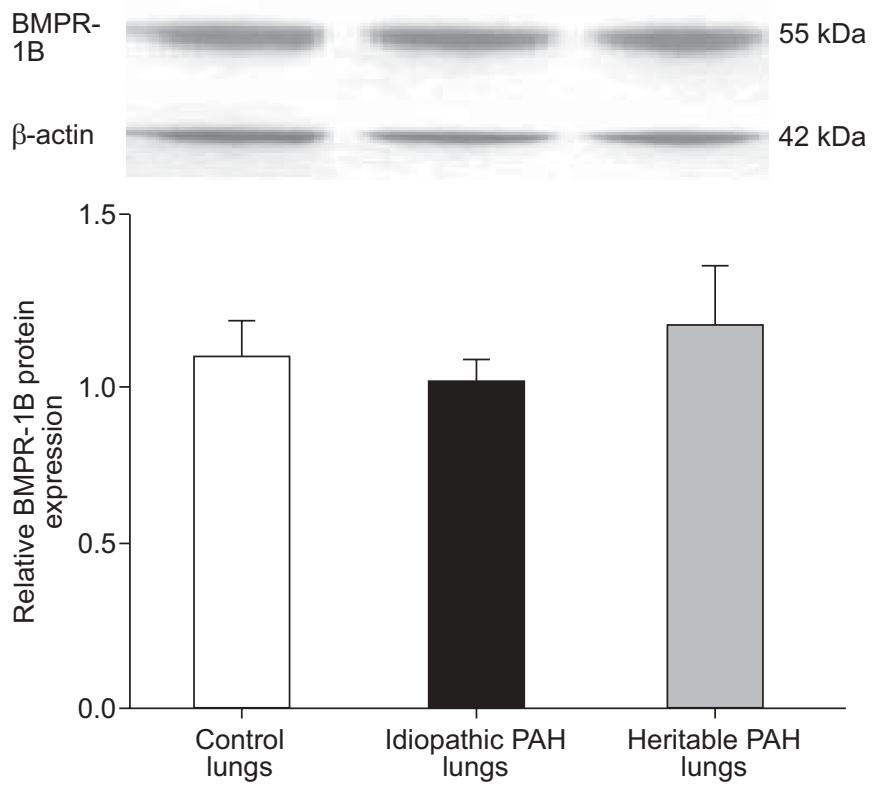

FIGURE 3. Relative a) bone morphogenetic protein receptor type $1 \mathrm{~A}$ (BMPR1A), b) BMPR-1B and c) BMPR-2 protein expression in whole lung tissue samples from controls $(\square)$, pulmonary arterial hypertension (PAH) patients without ( idiopathic PAH) and with BMPR-2 mutations ( $\square$; heritable PAH) were assessed by western blotting. Results are expressed as mean \pm SEM and as expression relative to $\beta$-actin. Statistical differences were assessed by the Mann-Whitney test. *: $p<0.05$ versus control conditions; $\#: p<0.05$ idiopathic $\mathrm{PAH}$ versus heritable $\mathrm{PAH}$ conditions.

idiopathic $\mathrm{PAH}$, but this is probably related to minor phenotypic differences, individual variability and small sample size.

Our results confirm that the expression of BMPR-2 is decreased in idiopathic PAH and much more decreased in heritable $\mathrm{PAH}$ [21]. The relative magnitudes of lung tissue and isolated PASMC and PEC expression were suggestive of a predominant PASMC location of BMPR-2. This is in contrast with predominant endothelial cell location previously reported in normal controls and in lungs from PAH patients [21]. However, recent studies on human PASMCs and PECs showed relatively high levels of BMPR-2 on both cell types, 

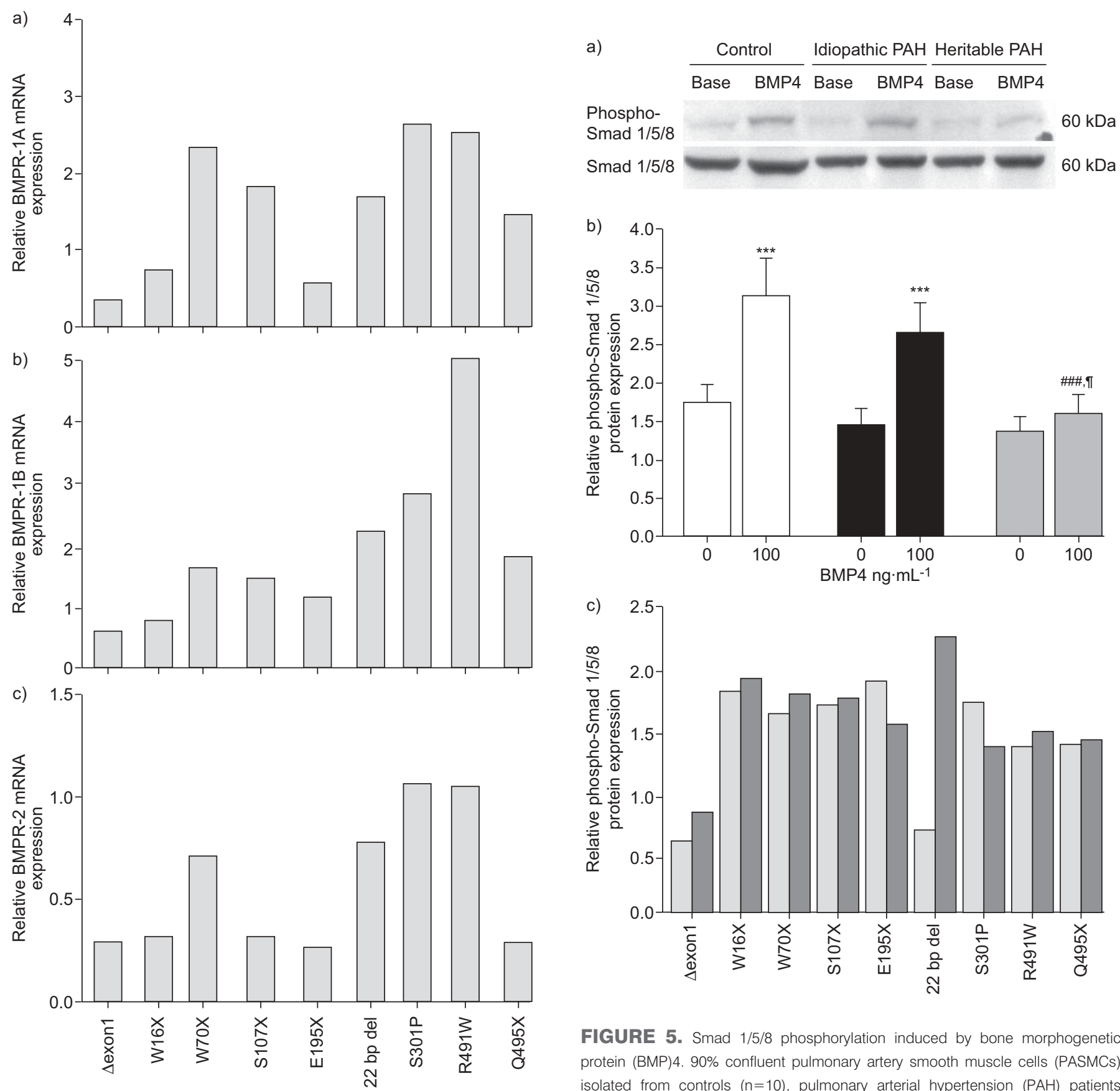

FIGURE 4. Relative a) bone morphogenetic protein receptor type 1A (BMPR1A), b) BMPR-1B and c) BMPR-2 mRNA expression in pulmonary artery smooth muscle cells isolated from heritable pulmonary arterial hypertension patients with naturally occurring BMPR-2 mutations ( $\triangle$ exon1, G/A=W16X, G/A=W70X, C/ $\mathrm{G}=\mathrm{S} 107 \mathrm{X}, \mathrm{G} / \mathrm{T}=\mathrm{E} 195 \mathrm{X}, 22 \mathrm{bp}$ del, $\mathrm{T} / \mathrm{C}=\mathrm{S} 301 \mathrm{P}, \mathrm{C} / \mathrm{T}=\mathrm{R} 491 \mathrm{~W}$ and $\mathrm{C} / \mathrm{T}=\mathrm{Q} 495 \mathrm{X})$. Results were assessed by real-time quantitative PCR.

but very low expression of BMPR-1A and $-1 \mathrm{~B}$ in PECs, consistent with a lack of BMP4 responsiveness [22]. In the present study, the expression of BMPR-2, BMPR-1A and BMPR-1B was much lower in PECs compared with PASMCs, with no apparent impact of BMPR-2 mutations, so that further analysis focused on PASMCs. Moreover, in heritable PAH

FIGURE 5. Smad 1/5/8 phosphorylation induced by bone morphogenetic protein (BMP)4. 90\% confluent pulmonary artery smooth muscle cells (PASMCs) isolated from controls $(n=10)$, pulmonary arterial hypertension (PAH) patients without (idiopathic $\mathrm{PAH} ; \mathrm{n}=10$ ) and with $\mathrm{BMP}$ receptor type 2 (BMPR-2) mutations (heritable PAH; $\mathrm{n}=9$ ) were stimulated with $100 \mathrm{ng} \cdot \mathrm{mL}^{-1} \mathrm{BMP} 4$ for $20 \mathrm{~min}$, followed by lysis for total protein. a) Representative western blots for phospho-Smad 1/5/8 and for total Smad 1/5/8 to show equal loading. b) Densitometry of phospho-Smad $1 / 5 / 8$ and total Smad $1 / 5 / 8$ bands from western blots of control ( $\square$ ), idiopathic PAH

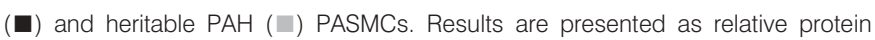
expression ratio of phospho-Smad1/5/8 and total Smad1/5/8 band intensity. Data are presented as mean \pm SEM. ${ }^{* *}: \mathrm{p}<0.001$ versus basal conditions in nonstimulated PASMCs; \#\#: $p<0.001$ versus value for PASMCs isolated from controls stimulated with BMP4; " $p<0.05$ versus value for PASMCs isolated from idiopathic PAH patients stimulated with BMP4. c) Relative densitometry ratio of phosphoSmad 1/5/8 in PASMCs isolated from defined naturally occurring BMPR-2 mutated patients $(\Delta$ exon1, G/A=W16X, G/A=W70X, C/G=S107X, G/T=E195X, 22 bp del, T/ $\mathrm{C}=\mathrm{S} 301 \mathrm{P}, \mathrm{C} / \mathrm{T}=\mathrm{R} 491 \mathrm{~W}, \mathrm{C} / \mathrm{T}=\mathrm{Q} 495 \mathrm{X}) . \quad \mathrm{a}$ : nonstimulated; $\mathbf{\square}$ : stimulated with $100 \mathrm{ng} \cdot \mathrm{mL}^{-1} \mathrm{BMP} 4$. 
a)
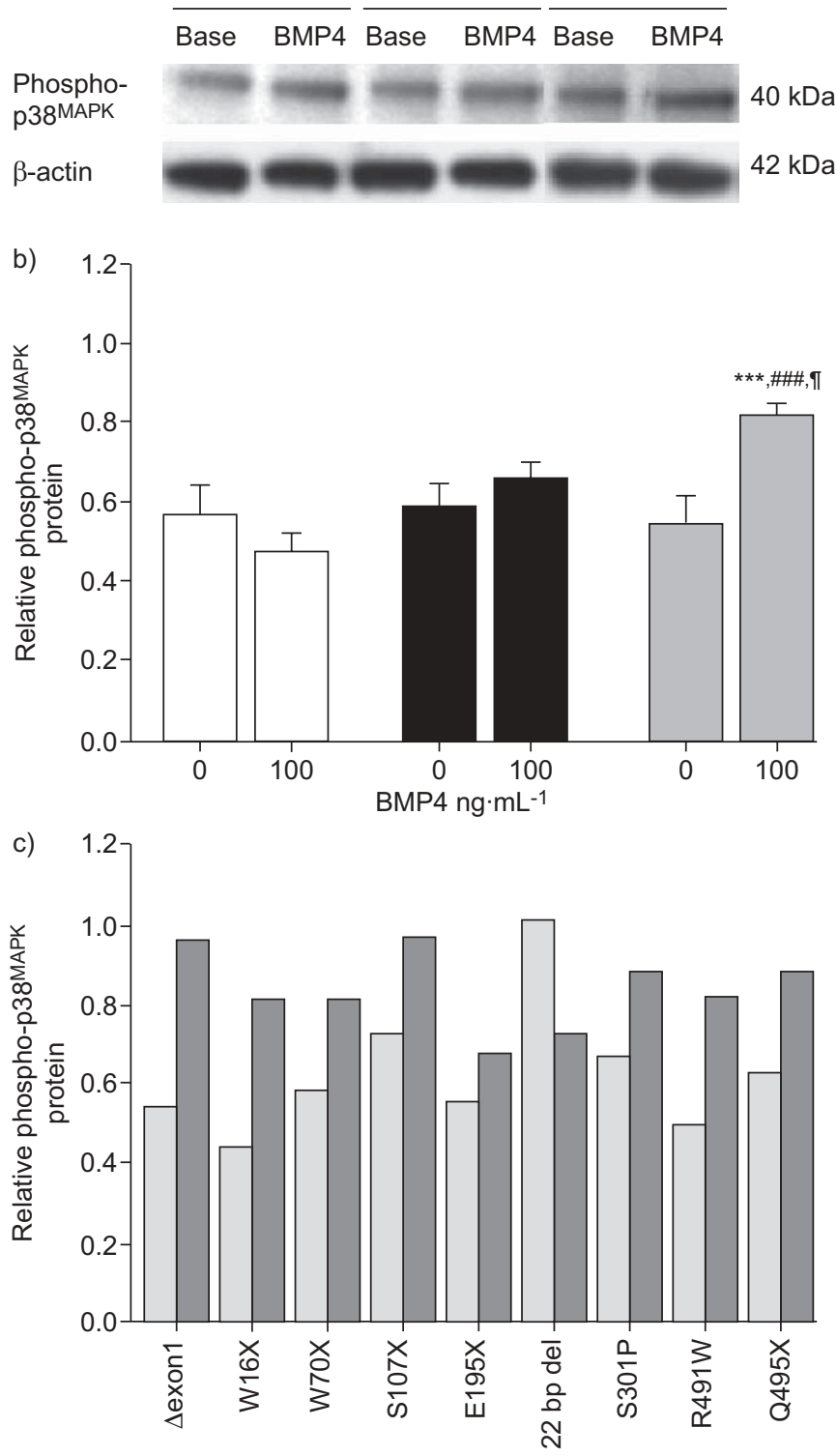

FIGURE 6. p38 mitogen-activated protein kinase (MAPK) phosphorylation induced by bone morphogenetic protein (BMP) 4 . 90\% confluent pulmonary artery smooth muscle cells (PASMCs) isolated from controls $(n=10)$, pulmonary arterial hypertension (PAH) patients without (idiopathic $\mathrm{PAH} ; \mathrm{n}=10$ ) and with $\mathrm{BMP}$ receptor type 2 (BMPR-2) mutations (heritable PAH; $\mathrm{n}=9$ ) were stimulated with $100 \mathrm{ng} \cdot \mathrm{mL}^{-1}$ BMP4 for 20 min, followed by lysis for total protein. a) Representative western blots for phospho-p38 and for $\beta$-actin to show equal loading. b) Densitometry of phospho-p38 and $\beta$-actin bands from western blots of control $(\square)$, idiopathic PAH (匹) and heritable PAH (匹) PASMCs. Results are presented as relative protein expression ratio of phospho-p38 and $\beta$-actin band intensity. Data are presented as mean \pm SEM. ${ }^{* * *}: p<0.001$ versus basal conditions in nonstimulated PASMCs; \#\#\#: $p<0.001$ versus value for PASMCs isolated from controls stimulated with BMP4; " $p<0.05$ versus value for PASMCs isolated from idiopathic PAH patients stimulated with BMP4. c) Relative densitometry ratio of phospho-p38MAPK in PASMCs isolated from defined naturally occurring BMPR-2 mutated patients ( $\Delta$ exon1, G/A=W16X, G/A=W70X, C/G=S107X, G/T=E195X, 22 bp del, T/ $\mathrm{C}=\mathrm{S} 301 \mathrm{P}, \mathrm{C} / \mathrm{T}=\mathrm{R} 491 \mathrm{~W}, \mathrm{C} / \mathrm{T}=\mathrm{Q} 495 \mathrm{X}) . \quad$ : nonstimulated; $\mathbf{\square}$ : stimulated with $100 \mathrm{ng} \cdot \mathrm{mL}^{-1} \mathrm{BMP} 4$

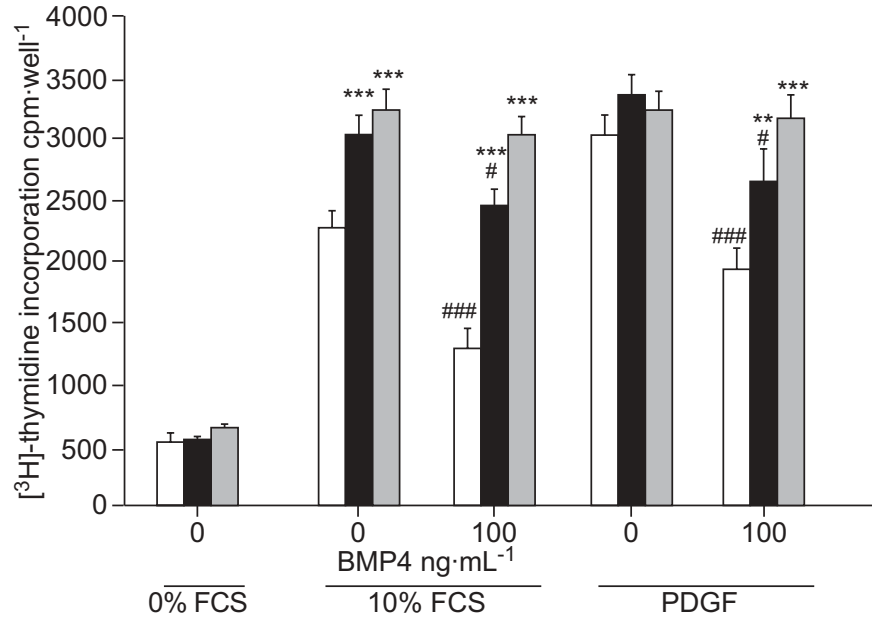

FIGURE 7. Basal $\left[{ }^{3} \mathrm{H}\right]$-thymidine incorporation in pulmonary artery smooth muscle cells (PASMCs) derived from controls $(\square ; n=10)$, pulmonary arterial hypertension (PAH) patients without ( $\mathbf{\square}$; idiopathic $\mathrm{PAH} ; \mathrm{n}=19$ ) and with bone morphogenetic protein (BMP) receptor type 2 mutations ( $\square$; heritable PAH; $n=9$ ) in response to incubation with or without BMP4 $\left(100 \mathrm{ng} \cdot \mathrm{mL}^{-1}\right)$, in the presence of $10 \%$ fetal calf serum (FCS) or $10 \mathrm{ng} \cdot \mathrm{mL}^{-1}$ platelet-derived growth factor (PDGF). Data are presented as mean \pm SEM. ${ }^{* *}: p<0.01$ versus PASMCs isolated from controls; $* * *: p<0.001$ versus PASMCs isolated from controls; $\#: p<0.05$ versus basal conditions in BMP4-nonstimulated PASMCs; ${ }^{\# \# \#: ~} p<0.001$ versus basal conditions in BMP4-nonstimulated PASMCs.

patients, the level of BMPR-2 expression was lower than predicted by the state of haploinsufficiency and the process of nonsense-mediated decay secondary to the presence of nonsense mutations. These observations are in keeping with the notion that some additional environmental and/or genetic factors may be responsible to further reduce BMPR-2 expression.

Decreased expression of BMPR-2 has also been reported to occur in experimental animal models of pulmonary hypertension, such as those induced by chronic systemic-to-pulmonary shunting [23], hypoxic exposure [24] and monocrotaline [25]. In the latter study, decreased BMPR-2 expression was described in both lung tissue and PASMCs [25]. Suprisingly, exclusive overexpression of BMPR-2 by gene therapy did not ameliorate monocrotaline-induced $\mathrm{PAH}$ in rats [26], indicating that reconstitution of the receptor was unable to restore BMP signalling and, thus, did not prevent disease onset or progression. The present results suggest that decreased expression associated with mutations in BMPR-2 seems to be crucial to explain the pro-proliferative and anti-apoptotic effects in PASMCs.

In the present study, the expression of BMPR-1A and BMPR$1 \mathrm{~B}$ tended to increase, although quite variably, with significant increases of BMPR-1A in lung tissue of both heritable and idiopathic PAH patients but only in PASMCs from idiopathic PAH patients, and of BMPR-1B in PASMCs from heritable PAH patients. The expression of BMPR-1A was decreased in a study on patients with various causes of severe pulmonary hypertension, including $\mathrm{PAH}$, but also mitral stenosis and thromboembolic pulmonary hypertension, and this was explained in relation to an overexpression of angiopoietin-1 

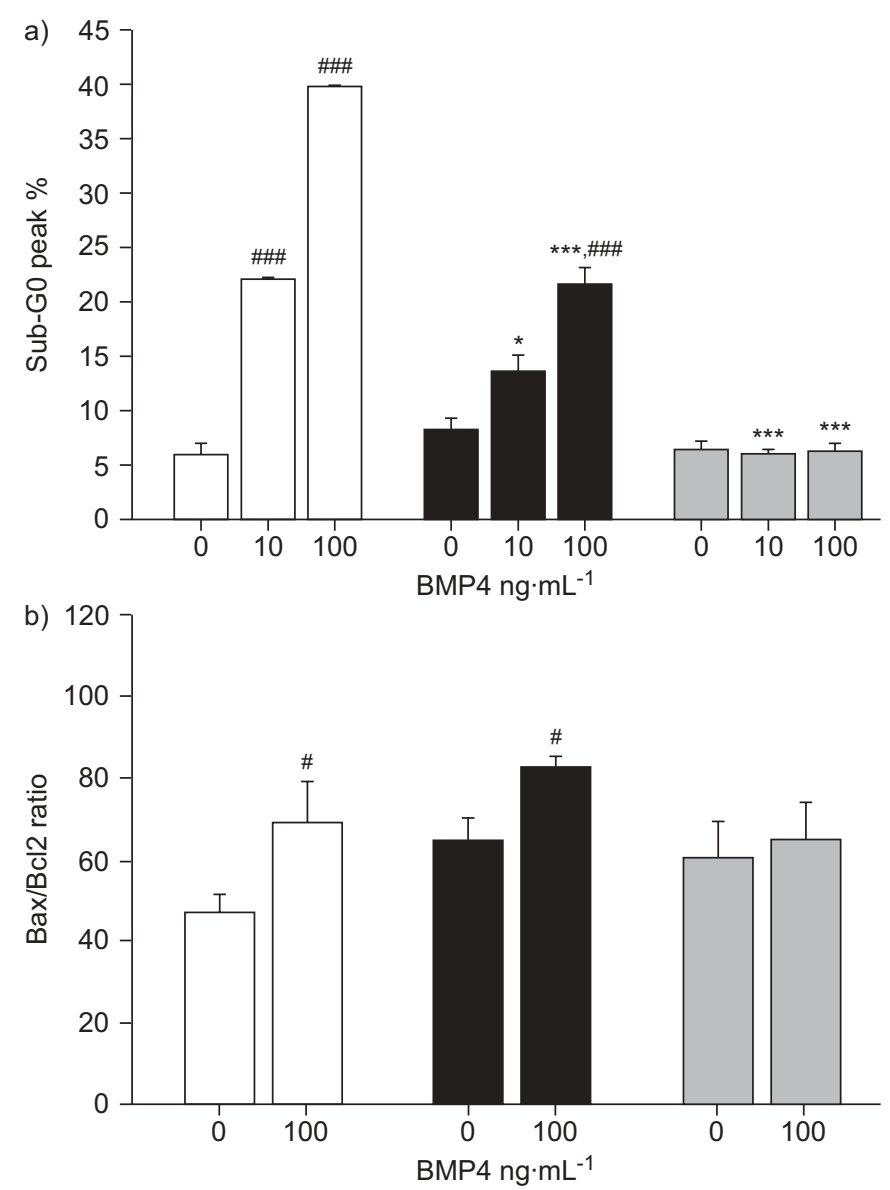

FIGURE 8. Bone morphogenetic protein (BMP)4-induced apoptosis of pulmonary artery smooth muscle cells (PASMCs) isolated from controls ( $\square$ $\mathrm{n}=10$ ), pulmonary arterial hypertension (PAH) patients without ( idiopathic $\mathrm{PAH} ; \mathrm{n}=10$ ) and with BMP receptor type 2 mutations ( $\square$ heritable PAH; $\mathrm{n}=9$ ). a) Flow cytometric analysis of propidium iodide-stained PASMCs treated with 10 and $100 \mathrm{ng} \cdot \mathrm{mL}^{-1} \mathrm{BMP} 4$ to evaluate the distribution of cells in different phases of the cell cycle. Apoptotic cells are evaluated as percentage sub-G0/G1 phase of cell population. b) Apoptotic index (Bax/Bcl-2 ratio) of PASMCs that were seeded, synchronised for $48 \mathrm{~h}$ and treated with $100 \mathrm{ng} \cdot \mathrm{mL}^{-1} \mathrm{BMP} 4$. Relative mRNA expression (Bax/Bcl-2) ratio was determined by real-time quantitative PCR. Data are presented as mean \pm SEM. ${ }^{*}: p<0.05$ versus similarly treated PASMCs isolated from controls; $* * *: p<0.001$ versus similarly treated PASMCs isolated from controls; ${ }^{*}: p<0.05$ versus basal conditions in BMP4-nonstimulated PASMCs; $\# \#$ : $p<0.001$ versus basal conditions in BMP4-nonstimulated PASMCs.

[27]. The expression of BMPR-2 was unaltered in that study [27]. We previously reported RTQ-PCR and western blotting of unchanged expression of angiopoietin-1 in whole lung tissue and in PASMCs from PAH patients [14]. In monocrotalineinduced pulmonary hypertension, the expression of BMPR-2 and BMPR-1B was decreased, while the expression of BMPR$1 \mathrm{~A}$ remained unchanged [25]. An increased expression of BMPR-1B has been reported in one idiopathic PAH patient [28]. The reasons for these discrepant results are unclear. Since BMPR-1A/BMPR-2 is the main BMP4-responsive receptor complex allowing for Smad $1 / 5 / 8$ stimulation [22], the overexpression of BMPR-1A in the PASMCs of the idiopathic $\mathrm{PAH}$ patients could be somehow related to the normal BMP4 responsiveness of these cells. As for the overexpression of BMPR-1B in heritable PAH, this could be speculated to be related to alternative $\mathrm{p} 38 \mathrm{MAPK}$ signalling activation.

Of the nine mutations identified in the present study, the W16X, R491W and Q495X have been previously reported [11, $29,30]$. The six other mutations (Aexon1, W70X, S107X, E195X, 22 bp del and S301P), across all four domains of the receptor, are all novel, including one total deletion of an exon, three nonsense mutations, one partial deletion and one missense mutation. Previous studies showed that missense mutations in the ligand-binding domain by cysteine substitutions impair BMP signalling by mutant receptor mislocalisation in the cytosol [31]. Moreover, noncysteine substitutions localise to the cell surface but also exhibit defects in BMP signalling activity [31]. In contrast, mutations in the cytoplasmic C-terminal domain only moderately inhibit Smad signalling [31, 32]. Therefore, in the present study, all reported mutations would be susceptible to be deleterious by changing the protein sequence at important functional sites of the receptor and the associated protein functions.

Mutations of BMPR-2 (including R491W) heterogeneously interfere with BMP downstream signalling, but all of them activate proliferative pathways [24]. We previously reported that PASMCs isolated from idiopathic PAH patients present with enhanced growth responses to serum, but not to PDGF [10]. In the present study, PASMCs with or without BMPR-2 mutations did not behave differently in this respect, but BMP4induced growth inhibition and increased apoptosis was markedly more important in PASMCs with BMPR-2 mutations. It is of interest that all the $B M P R-2$ mutations identified in the present study, except the $22 \mathrm{bp}$ deletion in the transmembrane domain, responded homogeneously to these effects of BMP4, supporting the notion that the majority of $B M P R-2$ mutations are functionally linked. Along the same line, decreased BMPR-2 expression in monocrotaline-induced pulmonary hypertension has been reported to be associated with decreased phosphorylation of Smad1 and a decrease in BMP-induced apoptosis of PASMCs [25].

In the present study, the application of BMP4 was associated in PASMCs with BMPR-2 mutations with a decreased activation (phosphorylation) of Smad 1/5/8 together with an increased activation (phosphorylation) of the p38MAPK pathway. We selected a dose of BMP4 of $100 \mathrm{ng} \cdot \mathrm{mL}^{-1}$ on the basis of available literature $[18,19,32]$ and preliminary testing showing maximum efficacy of $100 \mathrm{ng} \cdot \mathrm{mL}^{-1}$ compared with $10 \mathrm{ng} \cdot \mathrm{mL}^{-1}$ and $1 \mathrm{ng} \cdot \mathrm{mL}^{-1}$ in discriminating PASMCs with and without BMPR-2 mutations. However, a recent study showed maximum efficacy at a lower dose of $10 \mathrm{ng} \cdot \mathrm{mL}^{-1}$ of BMP4 [33]. The reasons for these discrepancies are not clear, and therefore the absence of complete dose-response curves may be a limitation to our findings. In monocrotaline-induced pulmonary hypertension, decreased BMPR-2 and phospho-Smad1 occurred without change in p38MAPK signalling in PASMCs [25]. In hypoxia-induced pulmonary hypertension, downregulation of BMPR-2 did not affect Smad 1/5/8 phosphorylation, and was associated with decreased p38MAPK signalling [24]. Although part of these differences may be related to model specificities and PASMCs versus whole lung measurements, the present 
data confirm previous reports $[31,32]$ that most mutations of $B M P R-2$ are associated with more profound changes in downstream signalling and are associated with increased p38MAPK signalling as a cause of increased PASMC proliferation.

The present results support the notion of altered BMPR-2/ Smad signalling as a cause of increased proliferation of PASMCs playing an important role in the remodelling of pulmonary resistance vessels in PAH.

\section{SUPPORT STATEMENT}

This study was supported by grants from the Institut National de la Santé et de la Recherche Médicale, the Ministère de la Recherche, the Institut des Maladies Rares, the Délégation à la Recherche Clinique de l'Assistance Publique - Hôpitaux de Paris (all Paris, France), the Belgian Foundation for Cardiac Surgery and from the Fonds de la Recherche Scientifique Médicale (grant no. 3.4551.05; both Brussels, Belgium). This research project received financial support from the European Commission under the 6th Framework Programme (contracts LSHMCT-2005-018275 and LSHM-CT-2005-018724, PULMOTENSION). This publication reflects only the authors' views, and under no circumstances is the European Community liable for any use that may be made of the information it contains.

\section{STATEMENT OF INTEREST}

None declared.

\section{REFERENCES}

1 Farber HW, Loscalzo J. Pulmonary arterial hypertension. $N$ Engl J Med 2004; 351: 1655-1665.

2 Newman JH, Trembath RC, Morse JA, et al. Genetic basis of pulmonary arterial hypertension: current understanding and future directions. J Am Coll Cardiol 2004; 43: 33S-39S.

3 Machado RD, Aldred MA, James V, et al. Mutations of the TGF- $\beta$ type II receptor BMPR2 in pulmonary arterial hypertension. Hum Mutat 2006; 27: 121-132.

4 Liu F, Ventura F, Doody J, et al. Human type II receptor for bone morphogenic proteins (BMPs): extension of the two-kinase receptor model to the BMPs. Mol Cell Biol 1995; 15: 3479-3486.

5 Moore RK, Otsuka F, Shimasaki S. Molecular basis of bone morphogenetic protein-15 signaling in granulosa cells. J Biol Chem 2003; 278: 304-310.

6 Ono M, Sawa Y, Mizuno S, et al. Hepatocyte growth factor suppresses vascular medial hyperplasia and matrix accumulation in advanced pulmonary hypertension of rats. Circulation 2004; 110: 2896-2902.

7 Elliott CG, Glissmeyer EW, Havlena GT, et al. Relationship of BMPR2 mutations to vasoreactivity in pulmonary arterial hypertension. Circulation 2006; 113: 2509-2515.

8 Sztrymf B, Coulet F, Girerd B, et al. Clinical outcomes of pulmonary arterial hypertension in carriers of BMPR2 mutation. Am J Respir Crit Care Med 2008; 177: 1377-1383.

9 Eddahibi S, Guignabert C, Barlier-Mur AM, et al. Cross talk between endothelial and smooth muscle cells in pulmonary hypertension: critical role for serotonin-induced smooth muscle hyperplasia. Circulation 2006; 113: 1857-1864.

10 Marcos E, Fadel E, Sanchez O, et al. Serotonin-induced smooth muscle hyperplasia in various forms of human pulmonary hypertension. Circ Res 2004; 94: 1263-1270.

11 Deng Z, Morse JH, Slager SL, et al. Familial primary pulmonary hypertension (gene PPH1) is caused by mutations in the bone morphogenetic protein receptor-II gene. Am J Hum Genet 2000; 67: 737-744.

12 Lane KB, Machado RD, Pauciulo MW, et al. Heterozygous germline mutations in BMPR2, encoding a TGF- $\beta$ receptor, cause familial primary pulmonary hypertension. The International PPH Consortium. Nat Genet 2000; 26: 81-84.

13 Eddahibi S, Humbert M, Fadel E, et al. Serotonin transporter overexpression is responsible for pulmonary artery smooth muscle hyperplasia in primary pulmonary hypertension. J Clin Invest 2001; 108: 1141-1150.

14 Dewachter L, Adnot S, Fadel E, et al. Angiopoietin/Tie2 pathway influences smooth muscle hyperplasia in idiopathic pulmonary hypertension. Am J Respir Crit Care Med 2006; 174: 1025-1033.

15 Hewett PW, Murray JC. Immunomagnetic purification of human microvessel endothelial cells using Dynabeads coated with monoclonal antibodies to PECAM-1. Eur J Cell Biol 1993; 62: 451-454.

16 Chomczynski P, Sacchi N. Single-step method of RNA isolation by acid guanidinium thiocyanate-phenol-chloroform extraction. Anal Biochem 1987; 162: 156-159.

17 Bradford MM. A rapid and sensitive method for the quantitation of microgram quantities of protein utilizing the principle of protein-dye binding. Anal Biochem 1976; 72: 248-254.

18 Morrell NW, Yang X, Upton PD, et al. Altered growth responses of pulmonary artery smooth muscle cells from patients with primary pulmonary hypertension to transforming growth factor- $\beta 1$ and bone morphogenetic proteins. Circulation 2001; 104: 790-795.

19 Sobolewski A, Rudarakanchana N, Upton PD, et al. Failure of bone morphogenetic protein receptor trafficking in pulmonary arterial hypertension: potential for rescue. Hum Mol Genet 2008; 17: 3180-3190.

20 Winer BJ, Brow DR, Michels KM. Statistical Principles in Experimental Design. 3rd Edn. New York, MacGraw-Hill, 1991; pp. 220-283.

21 Atkinson C, Stewart S, Upton PD, et al. Primary pulmonary hypertension is associated with reduced pulmonary vascular expression of type II bone morphogenetic protein receptor. Circulation 2002; 105: 1672-1678.

22 Upton PD, Long L, Trembath RC, et al. Functional characterization of bone morphogenetic protein binding sites and Smad1/5 activation in human vascular cells. Mol Pharmacol 2008; 73: 539-552.

23 Rondelet B, Kerbaul F, Van Beneden R, et al. Signaling molecules in overcirculation-induced pulmonary hypertension in piglets: effects of sildenafil therapy. Circulation 2004; 110: 2220-2225.

24 Takahashi H, Goto N, Kojima Y, et al. Down-regulation of type II bone morphogenetic protein receptor in hypoxic pulmonary hypertension. Am J Physiol Lung Cell Mol Physiol 2005; 290: L450-L458.

25 Morty RE, Nejman B, Kwapiszewska G, et al. Dysregulated bone morphogenetic protein signaling in monocrotaline-induced pulmonary arterial hypertension. Arterioscler Thromb Vasc Biol 2007; 27: 1072-1078.

26 McMurtry MS, Moudgil R, Hashimoto K, et al. Overexpression of human bone morphogenetic protein receptor II does not ameliorate monocrotaline pulmonary arterial hypertension. Am J Physiol Lung Cell Mol Physiol 2006; 292: L872-L878.

27 Du L, Sullivan CC, Chu D, et al. Signaling molecules in nonfamilial pulmonary hypertension. $N$ Engl J Med 2003; 348: 500-509.

28 Takeda M, Otsuka F, Nakamura K, et al. Characterization of the bone morphogenetic protein (BMP) system in human pulmonary arterial smooth muscle cells isolated from a sporadic case of primary pulmonary hypertension: roles of BMP type IB receptor (activin receptor-like kinase-6) in the mitotic action. Endocrinology 2004; 145: 4344-4354.

29 Koehler R, Grunig E, Pauciulo MW, et al. Low frequency of BMPR2 mutations in a German cohort of patients with sporadic 
idiopathic pulmonary arterial hypertension. J Med Genet 2004; 41: e127.

30 Machado RD, Pauciulo MW, Thomson JR, et al. BMPR2 haploinsufficiency as the inherited molecular mechanism for primary pulmonary hypertension. Am J Hum Genet 2001; 68: 92-102.

31 Rudarakanchana N, Flanagan JA, Chen H, et al. Functional analysis of bone morphogenetic protein type II receptor mutations underlying primary pulmonary hypertension. Hum Mol Genet 2002; 11: 1517-1525.
32 Yang X, Long L, Southwood M, et al. Dysfunctional Smad signaling contributes to abnormal smooth muscle cell proliferation in familial pulmonary arterial hypertension. Circ Res 2005; 96: 1053-1063.

33 Yang J, Davies RJ, Southwood $\mathrm{M}$, et al. Mutations in bone morphogenetic protein type II receptor cause dysregulation of Id gene expression in pulmonary artery smooth muscle cells: implications for familial pulmonary arterial hypertension. Circ Res 2008; 102: 1212-1221. 